\title{
DIREITO AO ESQUECIMENTO E DESINDEXAÇÃO DA INFORMAÇÃO
}

ambivalências e desafios no ambiente digital

\author{
Paulo Ricardo Silva Lima ${ }^{1}$ \\ Universidade Federal de Alagoas \\ pauloricardo.admpublic@gmail.com \\ João Rodrigo Santos Ferreira ${ }^{2}$ \\ Universidade Federal de Alagoas \\ joaorsferreira@gmail.com \\ Edivanio Duarte de Souza ${ }^{3}$ \\ Universidade Federal de Alagoas \\ edivanio.duarte@ichca.ufal.br
}

\begin{abstract}
Resumo
O desenvolvimento tecnológico promoveu o aumento de produção e compartilhamento de conteúdo em plataformas digitais, sendo difícil gerenciar o acesso adequado a informações. O presente artigo tem como objetivo discutir os efeitos do direito ao esquecimento no ambiente digital, considerando o processo de desindexação como estratégia para operacionalizar a efetividade desse direito. Tomando como referências arcabouços teóricosconceituais acerca da complexidade compósita da informação e de antinomias entre a dignidade da pessoa humana e a liberdade de expressão e o direito à informação, oriundos, respectivamente, da Ciência da Informação e do Direito, analisam-se e discutem-se algumas decisões jurisprudenciais e posicionamentos doutrinários no cenário brasileiro. $\mathrm{O}$ direito ao esquecimento está cercado de ambivalências e desafios de ordens normativa, tecnológica e cultural, num compartilhamento de informações em níveis sem precedentes que interferem negativamente na sua efetivação no ambiente digital.
\end{abstract}

Palavras-chave: Direito à informação. Direito ao esquecimento. Desindexação da informação. Liberdades individuais.

\section{RIGHT TO FORGET AND DEINDEXATION OF INFORMATION}

ambivalencies and challenges in the digital environment

\begin{abstract}
Technological development has increased the production and sharing of content on digital platforms, making it difficult to manage adequate access to information. This article aims to discuss the effects of the right to be forgotten in the digital environment, considering the deindexation process as a strategy to operationalize the effectiveness of this right. Taking as theoretical-conceptual frameworks about the composite complexity of information and antinomies between the dignity of the human person and freedom of expression and the right to information, originating, respectively, from Information Science and Law, they are analyzed and discussed some jurisprudential decisions and doctrinal positions on the Brazilian scene. The right to be forgotten is surrounded by ambiguities and challenges of a normative, technological and cultural order, in an information sharing at unprecedented levels that negatively interfere with its effectiveness in the digital environment.
\end{abstract}

Keywords: Right to information. Right to be forgotten. Deindexation of information. Individual freedoms.

\footnotetext{
${ }^{1}$ Mestrando em Ciência da Informação. Programa de Ciência da Informação da Universidade Federal de Alagoas.

${ }^{2}$ Mestrando em Ciência da Informação. Programa de Pós-Graduação em Ciência da Informação da Universidade Federal de Alagoas.

${ }^{3}$ Doutor em Ciência da Informação pela Escola de Ciência da Informação da Universidade Federal de Minas Gerais (2011). Professor Adjunto do Curso de Biblioteconomia do Instituto de Ciências Humanas, Comunicação e Artes da Universidade Federal de Alagoas.
} 


\section{INTRODUÇÃO}

A alta penetrabilidade, a celeridade e o amplo alcance presentes no ciberespaço, notadamente, nas mídias sociais, vem ampliando de modo sem precedente a liberdade infocomunicacional. $\mathrm{O}$ avanço tecnológico proporcionou a criação de ambientes digitais diversos destinados à produção, ao acesso e ao compartilhamento de informação. A dinamicidade e a alta penetrabilidade dessas plataformas alteraram os fluxos informacionais e as formas de interação, e passaram a compor o novo cenário infocomunicacional. Os aparatos tecnológicos como computadores, tablets e smartphones, entre outros, conectados à Internet não só alimentaram a curiosidade humana acerca da informação e conhecimento, como também ampliaram a liberdade de expressão e a capacidade de memorização.

Apesar dos inúmeros benefícios e conquistas, individuais, coletivos e difusos, provenientes dessa liberdade de expressão, que evidenciam o fortalecimento da democracia, é possível constar desordens infocomunicacionais emergentes que afetam as pessoas e a sociedade. Isso acontece, por exemplo, com o uso inapropriado de informações constrangedoras ou vexatórias com a intenção de prejudicar ou denegrir a imagem de outrem. O slogan "a Internet não esquece" tem trazido dissabores e prejuízos de ordens física, psíquica e social para as pessoas que já tiveram fatos constrangedores do passado rememorados nas mídias sociais. Para, pelo menos, minimizar o seu sofrimento, alguns países passaram a adotar o instituto do direito ao esquecimento, que tem como fundamento geral o direito à intimidade sobre fatos passados.

O direito ao esquecimento surge, no Brasil e mundo, como uma alternativa para sanar ou minimizar os problemas provenientes do mau uso da informação, principalmente, em ambientes digitais. Entretanto, o maior problema para eficácia desse direito no Brasil está no conflito entre este e outros direitos consagrados, inclusive, na Constituição Federal de 1988. De um lado há o direito à dignidade da pessoa humana e, do outro, os interesses coletivos e difusos consubstanciados, respectivamente, no direito à informação e no direito à memória.

Embora parte da doutrina e da jurisprudência brasileira tenha o entendimento de que o direito à dignidade deve prevalecer quando houver esse embate, existem casos em que o interesse coletivo prevalece. Há também os casos que dificultam ou mesmo impedem a retirada de uma informação do ciberespaço, pois o indivíduo lesado deve buscar identificar o produtor da informação ou o site hospedeiro e demandar contra estes, afastando-se, por exemplo, a responsabilização de provedores. 
Outro ponto importante no que tange à memória não esquecida pela sociedade da informação está na possibilidade de os usuários fazerem downloads e backups de informações em outras bases de dados dentro do ciberespaço, não existindo regulamento mais robusto que iniba essa ação. O direito ao esquecimento, apesar de ser um dispositivo legal que visa reduzir danos causados pela publicação de informações oriundas de ações vergonhosas do passado, não colabora, muitas vezes, em ambientes digitais.

Além disso, há casos em que informações lícitas e corretas são publicadas sem a intenção de ferir os direitos do indivíduo, cuja função principal é veicular uma informação de caráter público como, por exemplo, um crime contra os bens tutelados pela Carta Magna. Haveria, nesse caso, legalidade em retirá-la do ciberespaço? Não seria esta uma forma de censurar as mídias sociais? São questionamentos como estes que circulam no Judiciário brasileiro e para os quais ainda não há um posicionamento unânime entre os tribunais e que têm gerado dúvidas sobre a eficiência do direito ao esquecimento.

No contexto das novas plataformas digitais de comunicação em massa, esse esquecimento corresponde à retirada, por força legal, de uma determinada informação, dificultando ou inviabilizando sua localização ou até mesmo buscas sobre o conteúdo. No contexto Ciência da Informação, essa retirada de uma informação dos bancos de dados, que resulta em exclusão ou remoção, consiste em uma ação de desindexação da informação. Esse processo informacional se apresenta como uma estratégia para resolver as tensões e os problemas decorrentes do direito de acesso à informação e à vida privada, agravados pelo compartilhamento crescente e descontrolado de informações no ambiente digital.

As perguntas que emergem, nesse contexto, ultrapassam questões legais nacionais e soluções tecnológicas locais. É possível, por intermédio do Poder Judiciário, retirar do ambiente digital informações já amplamente disseminadas? E, de modo mais específico: É possível restabelecer a vida privada e a intimidade de pessoas que tiveram suas vidas expostas em plataforma digitais?

No Brasil, ainda não há legislação que trate exclusivamente do direito ao esquecimento no ambiente digital, o que dificulta sua concretização. Entretanto, o caminho a se percorrer não se situa exclusivamente na ausência de dispositivos legais que tratem desses problemas da sociedade contemporânea, mas em discutir conceitos e características da atual sociedade para melhor compreender como ela tem se organizado para lidar com problemas contemporâneos concretos, como, por exemplo, a desordem infocomunicacional e seus desdobramentos que alcançam direitos individuais, coletivos e difusos. Nesse contexto, destacam-se as dificuldades 
de desindexação de conteúdos espalhados em memórias digitais que podem, muitas vezes, ser recuperados aos sabores e dissabores de pessoas mal-intencionadas.

Nesse sentido, o presente artigo visa discutir os efeitos do direito ao esquecimento no ambiente digital, considerando o processo de desindexação como estratégia para operacionalizar a efetividade desse direito. Para tanto, tomando como referências teóricometodológicas um conjunto de aproximações e distanciamentos entre elementos da Ciência da Informação e do Direito contemporâneo, presentes na doutrina e na jurisprudência brasileira.

Do ponto de vista procedimental, a presente discussão tem como base pesquisas bibliográfica e documental, que, como orientam Lakatos e Marconi (2017), devem ser realizadas, respectivamente, em fontes resultantes de análises e discussões técnico-científicas e fontes primárias que ainda não passaram por aqueles processos analítico-discursivos. No que se refere à primeira, foram realizados levantamentos em bases de dados especializadas, principalmente, na Base de Dados da Ciência da Informação (BRAPCI) e na Scientific Electronic Library Online (SciELO), com o intuito de obter referenciais suficientes para abordar questões relacionadas à informação e à rede conceitual em torno do direito ao esquecimento. No que se refere à segunda, foram realizados levantamentos de instrumentos normativos e decisões acerca de casos concretos julgados que envolvem o direito ao esquecimento, com destaque para os mais conhecidos (BRASIL, 2012, 2013a, 2013b, 2014, 2015, 2020). Os instrumentos normativos se encontram nos Portais da Presidência da República Federativa do Brasil e a jurisprudência, nos Portais do Tribunais Superiores brasileiros.

\section{A INFORMAÇÃO NA SOCIEDADE CONTEMPORÂNEA: AMBIVALÊNCIAS E DESAFIOS}

A sociedade atual tem exaltado a comunicação interpessoal e valorizado a informação, dando a esta diferentes peculiaridades que vão desde sua equiparação a mera mercadoria, ao seu mérito como insumo de conhecimento, poder e transformações sociais. O avanço tecnológico vem provocando mudanças sem precedentes na sociedade em seus mais variados aspectos. Isso pode ser percebido, principalmente, na migração das relações pessoais do mundo físico para o espaço virtual.

A partir de análises amplas e profundas, em "A sociedade em rede", que integram aspectos sociais, econômicos e culturais, em diferentes partes do mundo, Castells (2000) demonstra que as relações interpessoais deram espaço às relações computacionais, nas quais as pessoas interagem cada vez mais por meio de computadores, celulares ou tablets conectados à 
Internet, criando uma rede de interação em que são disseminados e trocados informações, processos, produtos, experiências e culturas. Importante dizer que, na base desta sociedade, encontra-se a emergência de um novo modelo de desenvolvimento, o informacionalismo, que moldou o modo de produção capitalista exclusivamente nos limites das relações dinâmicas entre mão de obra e matéria-prima presentes nos processos produtivos. Ocorre que, como bem esclarecera Castells (2000), as sociedades são estruturadas a partir de relações de produção, experiência e poder. Isso, contudo, passa ao largo da compreensão superficial de determinismo de qualquer natureza, ausência de transformação e/ou imobilidade de ordens econômica, política, social e cultural.

Assim, essa infraestrutura, tecnológica e informacional, faz surgir uma nova organização social, distinta da industrial ou pós-industrial, que ganha, entre outras, denominações de "Sociedade da Informação", "Sociedade do Conhecimento", "Sociedade em Rede" e "Sociedade Aprendente", e evidencia seu caráter complexo, constituído por ambivalências, contradições e desafios de diferentes ordens.

A expressão "Sociedade da Informação", aqui utilizada, tornou-se popular nos anos 1970, momento em que a tecnologia e a ciência ganhavam novos ares com o advento da globalização e, concomitante, a informação passou a ser a principal fonte de sobrevivência das organizações industriais, pois os meios de comunicação baratearam procedimentos que levavam maior tempo para serem resolvidos, como negociações com fornecedores e clientes. Para além das organizações, é importante ressaltar que a informação integra todas as atividades do homem numa sociedade, sendo isto atingido pelas novas tecnologias (WERTHEIN, 2000).

Complementarmente, Bauman (1999) esclarece que o conceito de sociedade não se prende aos limites de tempo e espaço, e com isso o fluxo informacional encontra poucas barreiras intransponíveis para sua efetivação. O fato é que o espaço planejado pela sociedade já não se limita a arquiteturas físicas, sólidas e organizadas, pois contempla, na previsão de Lévy (1999), novos modelos de cadeias de interações, nos quais hardware e software são os principais responsáveis pela sua constituição. Essa nova modalidade de espaço, chamada de ciberespaço, é fruto da rede mundial de computadores.

A Sociedade da Informação também está atrelada à inovação tecnológica, que, por meio de novas ferramentas e canais de comunicação conectados à Internet, dinamizou, sem precedentes, o processamento, a transmissão e a recuperação de informação, tornando o fluxo informacional mais célere e eficiente. Essa sociedade, de acordo com Dantas (1996), é oriunda do desenvolvimento do capitalismo, uma etapa na qual o homem passou a exercer suas atividades sociais e econômicas mediadas por inovações tecnológicas. 
A nova ordem social está, também, intimamente ligada ao setor econômico, que, como pondera Demo (2000), se apresenta como um pano de fundo capitalista para criar uma falsa globalização informatizada, com um discurso positivista no qual todos os países seriam atingidos de forma igual, mas favoreceu o fortalecimento de países desenvolvidos como os Estados Unidos da América, China, Japão, Alemanha e Reino Unido, entre outros.

Em que pesem os desafios impostos pelas relações de produção, experiência e poder, a informação influencia diretamente todos os setores da sociedade, sejam eles o econômico, político, social e cultural, como também pode contribuir de forma incisiva para o desenvolvimento do cidadão, na medida em que desenvolve nele a capacidade crítica para orientar suas ações e reações perante os desafios que lhe são apresentados, e para atuar de forma mais ativa e autônoma no ambiente social, físico ou digital. $\mathrm{O}$ avanço tecnológico, a partir dos novos canais digitais, horizontalizou a comunicação, colocando, pelo menos, parte dos seus usuários em um processo crescente de interações. A intervenção popular no cenário social se tornou mais viável, inclusive com a possibilidade de diálogos para resolução de controvérsias entre diferentes setores sociais.

O fenômeno que melhor caracteriza esse novo funcionamento em rede é a convergência progressiva que ocorre entre produtores, intermediários e usuários em torno a recursos, produtos e serviços de informação afins. Os recursos, produtos e serviços de informação são identificados na Internet com o nome genérico de conteúdo. (MIRANDA, 2000, p. 80).

Fruto do desenvolvimento tecnológico, surgiram as redes sociais digitais, espaço no qual as pessoas compartilham e comungam gostos, desejos, sonhos e momentos. Porém, como reflexos das ambivalências e contradições que caracterizam as relações de produção, experiência e poder, essas redes aproximam os sujeitos e possibilitam o compartilhamento de informação verdadeiras, incompletas e/ou falsas que podem causar transtornos, pois contradizem preceitos éticos e morais necessários ao convívio pacífico entre sujeitos sociais.

As redes sociais, de modo geral, compreendem, no entendimento de Lozares (1996), um conjunto de sujeitos, organizações e comunidades que se organizam em relações sociais, como, por exemplo, grupo de empresários, trabalhadores, estudantes e pesquisadores. Essas organizações estão presentes nas redes sociais digitais, onde normalmente as conexões ocorrem em torno de vínculos sociais anteriores, como familiares e amigos (MARTELETO, 2001; GOLDER; WILKINSON; HUBERMAN, 2007; FAORO; ABREU; DEMARCHI, 2017).

Como observado por Boyd e Ellison (2008), os perfis criados em redes sociais digitais seguem algumas etapas. Primeiro, o sujeito escolhe a rede social de seu interesse, e, em seguida, inclui informações sobre ano de nascimento, cidade natal, cidade de residência, sexo e telefone, 
entre outras. Nesta fase cadastral, o sujeito realiza as primeiras autorizações, restrições e bloqueios sobre as informações a que outros usuários podem ter acesso. A partir do perfil criado, é comum que as redes já sugiram pessoas como possíveis conexões.

$\mathrm{Na}$ conformação da rede, o grupo constituído por familiares, parentes ou pessoas do ciclo de amizade é caracterizado pela manutenção de laços fortes, em decorrência de seus vínculos afetivos. Os laços externos a este círculo são mais fracos, mas são os que predominam nas interações mantidas no ciberespaço. O predomínio dos laços fracos é apontado por Bauman (2000) como um dos principais elementos da sociedade líquida, que se caracteriza pela mutabilidade, onde tudo muda rapidamente e nada é feito para durar.

Numa abordagem quantitativa, Martino (2015) considera, contudo, que esses laços fracos se fortalecem, na medida em que contemplam conexões entre uma grande quantidade de pessoas socialmente distantes. Isso contribui para que a disseminação de informações alcance pessoas que estão fora do círculo de intimidade e ganhe maiores proporções.

Malgrado as contradições e ambivalência em que se estruturam as relações sociais neste ambiente, Le Coadic (2004) observa que as tecnologias digitais são capazes de promover o desenvolvimento do processo informacional na sociedade, sobretudo, vinculado à institucionalização de serviços informacionais que geram uma rede de colaboração entre vários atores sociais. Agora, a sociedade contemporânea, materializada nas relações dinâmicas entre informações, sujeitos e tecnologias, traz alguns desafios a serem superados, dentre os quais estão o descontrole em relação às informações que são veiculadas no meio digital e as dificuldades de se manter a privacidade, numa cultura crescente de livre acesso e compartilhamento.

Primeiro, a informação possui uma série de conceitos, definições e aplicabilidades em diferentes áreas do conhecimento. Entretanto, em que pese essa multiplicidade do campo informacional, a Ciência da Informação apresenta algumas definições que possibilitam delimitá-la, conforme a abordagem e os objetivos dos estudos, considerando, em grande medida, a materialidade, a formalidade e as relações dinâmicas que a envolvem. Segundo, os processos informacionais têm como referências o sujeito informacional e suas necessidades de informar e ser informado, além das condições sociais amplas e tecnológicas, no mundo físico e no ambiente virtual, que compõem uma infraestrutura complexa de acessos diferenciados, inclusive promovendo uma crescente desordem da informação, que, segundo Wardle e Derakhshan (2019), contempla informação incorreta, informação falsa e má informação.

Nesse contexto, é importante considerar, a partir de Saracevic (2009), que a informação, seja ela correta ou incorreta, falsa ou verdadeira, boa ou má, é resultado de atividades humanas, 
um produto de grande valia para solucionar problemas do cotidiano. Entretanto, nem sempre há apropriação adequada da informação por questões diversas, como, por exemplo, os ambientes, as fontes, os recursos e as políticas, sendo necessário o planejamento de estratégicas que busquem melhorias dos processos informacionais. Assim, embora associad a à solução de problemas específicos, a informação pode contribuir para que o sujeito conheça e reconheça o contexto em que está inserido e, a partir desse, aja conforme os acordos sociais estabelecidos, sejam eles éticos, morais, normativos ou culturais.

Numa abordagem mais pragmática, tomando como referência a institucionalização da mediação da informação, Le Coadic (2004) pondera que, de modo geral, ela se refere a um tipo de conhecimento registrado na forma escrita, oral e visual, disponível, impressa ou digitalmente, em uma base, com a principal finalidade de gerar um conhecimento capaz de sanar uma necessidade social.

Esse entendimento tem como referências primeiras os processos de mediação da informação realizados por instituições de memória, tais como arquivos, bibliotecas, centros de documentação, museus e unidades de informações jornalísticas. Além dos limites destes espaços institucionais, os processos informacionais ganham novos contornos, muitas vezes, se não cuidadosamente planejados, disponibilizados e gerenciados, que alcançam a vida privada dos sujeitos e as grandes organizações sociais. Ocorre que a informação é um sistema aberto e, por conseguinte, pode assumir conotações diversas e ser usada com finalidades contrárias à boa dinâmica social. Com efeito, o impacto do uso indevido da informação se faz presente, por exemplo, em violações de intimidades, fraudes de processos eleitorais e movimentos negacionistas.

Partindo da complexidade da informação, sobretudo, relacionada ao seu caráter ambivalente, ora como entidade ora como processo, ora intangível ora tangível, Buckland (1991) demonstra que a informação é permeada por vários sentidos, sendo impossível dar a esta um significado universal que atenda às expectativas conceituais de todas as áreas do conhecimento e, menos ainda, das diversas abordagens e dos diferentes usos nessas diversas áreas. No entanto, o autor estabelece um quadrante que auxilia sobremaneira na compreensão do fenômeno informacional.

No domínio da entidade, Buckland (1991) situa a informação em dois polos, o objetivo (tangível) e o subjetivo (intangível). No primeiro, considera-se a estrutura significante da informação, que compõe qualquer coisa presente na natureza; no segundo, o significado atribuído pelo sujeito cognoscente àquelas estruturas, em um processo de apreensão da informação. O autor as denomina, respectivamente, de "informação como coisa" e "informação 
como conhecimento". No domínio do processo, em sentido amplo, situa a informação também dois polos, o processo, em sentido estrito, (intangível) e o processamento da informação (tangível). O primeiro compreende a construção da informação, e o segundo, os procedimentos adotados na estruturação e mediação da informação. O autor os denomina, respectivamente, de "informação como processo" e "processamento da informação". A entidade e o processo, nas esferas tangíveis, são direcionados à externalização da informação (informar), ao passo que, nas esferas intangíveis, são orientados à internalização da informação (informar-se).

Ao observar a complexidade compósita da informação, algumas questões críticas emergem, principalmente, ao se considerar a maleabilidade dos fluxos que a constituem, como sugere Castells (2000). Então, se, por um lado, a estruturação da informação possibilita a construção de memórias que contribuem com a manutenção da verdade histórica e a promoção do acesso à informação, entre outros, sob o manto da liberdade da informação, por outro lado, a ingerência desses elementos pode ter desdobramentos diversos que ferem direitos igualmente fundamentais, na sociedade contemporânea, como o direito à intimidade e à privacidade.

\section{O DIREITO AO ESQUECIMENTO NO BRASIL: DESAFIOS PARA A DESINDEXAÇÃO DE INFORMAÇÕES NA INTERNET}

A liberdade de pensamento e o direito à informação passaram a ser reconhecidos internacionalmente de forma mais expressiva a partir de 1948, sob a égide da Declaração Universal dos Direitos Humanos, que, em seu artigo 19, dispõe: “Todo indivíduo tem direito à liberdade de opinião e de expressão, o que implica o direito de não ser inquietado pelas suas opiniões e o de procurar, receber e difundir, sem consideração de fronteiras, informações e ideias por qualquer meio de expressão" (UNITED..., 1948, p. 5).

O Brasil vem fortalecendo gradativamente seus valores democráticos materializados na Constituição Federal de 1988, com a consolidação dos direitos individuais e coletivos, entre os quais se encontra o direito à informação. Com isso, o país passou a seguir uma tendência mundial que associa a liberdade de informação ao exercício da cidadania.

Com o surgimento e a ampliação dos canais digitais de informação esse direito de expressão ganhou força, visto que facilitou a comunicação e, consequentemente, deu maior liberdade de expressão à população em geral. Com efeito, essas tecnologias promoveram uma virada paradigmática na qual a memória passa a ser a regra, em detrimento do esquecimento, e torna o passado cada vez mais presente e, muitas vezes, onipresente. A questão crítica, já colocada por Consalter (2017), é que muitas pessoas, com o desejo de visibilidade e 
reconhecimento, desenvolvem a ânsia por eternizar toda e qualquer experiência e ingressam num processo crescente de superexposição que pode ter desdobramentos diversos e indesejados.

Antes da Internet, os canais de comunicação, como os jornais e revistas, já eram usados para disponibilizar informações, inclusive de caráter privado e íntimo, sobre as pessoas, porém, a propagação dessas tinha um menor alcance, haja vista que, por se tratar de objetos físicos, a sua recuperação, caso fosse possível, demandaria maior esforço do usuário para superar as barreiras de tempo e espaço. Esse esforço barrava os usuários menos curiosos e, consequentemente, essas informações estariam mais vulneráveis ao esquecimento. Porém, a chegada da Internet modificou completamente esse cenário; os sites e redes sociais digitais tornaram as informações mais acessíveis a qualquer interessado. A celeridade com que as informações são produzidas e compartilhadas nesses ambientes criou dificuldades na preservação da vida privada e da intimidade das pessoas.

Da mesma forma que esse relativo fácil acesso disponibiliza aos usuários um acervo de informações, coloca-os em posição vulnerável, pois ele pode conter informações de caráter pessoal e restrito. "É possível que [...] dados privados de pessoas que não desejam que suas informações estejam ao alcance de todos, sendo universalmente e globalmente divulgados, durante um prazo indeterminado e ilimitado, possam afetar os direitos da personalidade e, em suma, a sua dignidade" (MARTINEZ, 2014, p. 57).

É certo que a capacidade humana de recordar independe dos mecanismos derivados do avanço tecnológico. Entretanto, como forma de facilitar o acesso à informação, esses mecanismos trazem à tona, muitas vezes, sem filtros, assuntos que já não merecem mais serem discutidos. Acontece que, mesmo quando a máquina não sugere, ela facilita o processo de busca e dá ao usuário, sem alguns critérios de seleção, aquilo que ele procura e que está disponível na rede.

O esquecimento, neste contexto ambivalente, é tão importante quanto a memória, mas existem alguns entraves para que aquele aconteça. "A permanência das informações no mundo virtual remete, metaforicamente, à ideia de rastro psíquico. O acesso a esses rastros seria intermediado pelos motores de busca, que 'rastreiam', de fato, o espaço virtual em busca de informação" (RODRIGUES; OLIVEIRA, 2015, p. 98, grifo das autoras). Nesse sentido, mesmo que uma informação tenha caído no esquecimento, as condições do mundo virtual oferecem mecanismos que levam à sua rememoração. Nesse caso, a ação de esquecimento deve impedir que esses mecanismos eletrônicos de busca sinalizem para a recuperação da informação objeto 
de supressão. No contexto de rastros, Ricoeur (2010, p. 425) esclarece a discussão sobre rastro psíquico da seguinte forma:

Desde o comentário dos textos de Platão e Aristóteles, fundamentados na metáfora da impressão na cera, propus distinguir três espécies de rastros: o rastro escrito, que se tornou, no plano da operação historiográfica, rastro documental; o rastro psíquico, que é preferível chamar de impressão, no sentido da afecção, deixada em nós por um acontecimento marcante ou, como se diz, chocante; enfim, o rastro cerebral, cortical, tratado pelas neurociências.

Os rastros psíquicos fazem parte do imaginário das pessoas, pois, quando um fato que tem grande repercussão, impossibilita o esquecimento em sua totalidade, tornando-se um fantasma fragmentado, que a qualquer tempo pode voltar a ser discutido nos ambientes sociais, principalmente, por causa das facilidades propostas pelos novos canais sociais de comunicação. No Brasil, tem-se como exemplos os assassinatos da atriz Daniella Perez, no Rio de Janeiro, em 1992, e da criança Izabella de Oliveira Nardoni, em São Paulo, em 2002, que causaram grande comoção popular e receberam ampla cobertura da imprensa nacional. Esses acontecimentos permanecem no tempo, uma vez que, para usar as palavras de Ricouer (2010), são objeto de recordação e rememoração periódicas como exemplos de crimes hediondos.

Ao colocar a produção, o compartilhamento e a apropriação da informação nas esferas da recordação e rememoração, é importante problematizar sobre as liberdades individuais e o direito geral de personalidade, em especial, o direito ao resguardo da vida íntima (intimidade) e privada (privacidade) do indivíduo. É forçoso considerar que, no entendimento de Mazzuoli (2019), o direito à comunicação no universo digital é garantido a todo cidadão que queira expressar suas ideias e opiniões sobre assuntos de cunho religioso, científico ou artístico. Porém, quando esses conteúdos ferem direitos fundamentais, a pessoa que se sentir lesada, sobretudo, no seu direito à privacidade e à intimidade, com o teor das informações propagadas pode, conforme o caso, requerer exclusão via judicial.

Ocorre que, mesmo colocando o direito à informação sob o escopo dos direitos fundamentais e da personalidade, permanecem algumas situações em que aquele direito colide com outros igualmente direitos fundamentais. Assim, trata-se de sopesar as liberdades individuais na relação com o direito ao esquecimento, que incide sobre o direito à intimidade acerca de fatos pretéritos. Esse entendimento tem, conforme Simón Catellano (2012), como referência o princípio da autodeterminação informativa que, fundamentado na dignidade da pessoa humana, prevê o direito de cada sujeito controlar e proteger os próprios fatos e dados pessoais registrados, processados, disponibilizados e compartilhados na Internet. 
O direito ao esquecimento é visto por Cavalieri Júnior (2019) como o recurso que o indivíduo possui para se proteger da rememoração de fatos ocorridos no passado e que no presente lhe causariam algum tipo de dano. Assim, a pessoa que tenha o seu nome ou a sua imagem vinculada a um fato constrangedor em um suporte informacional, físico ou digital, pode angariar, junto ao Poder Judiciário, pelo menos, o direito à sua desvinculação.

Esse entendimento é corroborado por Chehab (2015), para quem o direito ao esquecimento é uma faculdade que o cidadão possui para ver apagado um fato seu do passado que no presente já não possui uma finalidade e que acaba ferindo direitos fundamentais. Assim, a informação de um fato ou ato realizado anteriormente por um indivíduo pode ser suprimida, bloqueada e apagada de determinada fonte de informação através da ação de direito ao esquecimento, inibindo, dessa forma, a propagação e, por conseguinte, a respectiva rememoração.

As abordagens acerca do direito ao esquecimento nos ambientes virtuais se deram após as discussões da Comissão do Parlamento Europeu quanto à proteção de dados de usuários na Internet na última década. Neste sentido, a referida Comissão aprovou em 2018 o Regulamento Geral de Proteção de Dados da União Europeia, mais conhecido como GDPR, do inglês General Data Protection Regulation. Neste documento, além de outras pontuações sobre dados pessoais, ficou estabelecido que os cidadãos europeus têm o direito de solicitar a retirada de dados pessoais do ambiente digital quando estes já não possuírem uma finalidade para se manterem expostos (FERREIRA, et al., 2018).

Esse novo problema colocou o Poder Judiciário brasileiro em uma situação crítica, tendo em vista as dificuldades de eliminar uma informação de um ambiente tão aberto, dinâmico e mutável, visitado por grande parcela da população mundial, que tem infinitas possibilidades de acessar, produzir, manipular e compartilhar informações. Inicialmente, como alternativa para sanar ou amenizar essa problemática, foi adaptada a ação do direito ao esquecimento para as publicações realizadas no ambiente virtual, conforme algumas decisões já tomadas e discussões presentes em parte da doutrina nacional.

Seguindo uma corrente internacional na aplicação do direito ao esquecimento, o Judiciário brasileiro, na VI Jornada de Direito Civil, promovida pelo Conselho da Justiça Federal (CJF) do STJ, no ano 2013, trouxe o Enunciado n $^{\circ} 531$ :

Os danos provocados pelas novas tecnologias de informação vêm-se acumulando nos dias atuais. O direito ao esquecimento tem sua origem histórica no campo das condenações criminais. Surge como parcela importante do direito do ex-detento à ressocialização. Não atribui a ninguém o direito de apagar fatos ou reescrever a própria história, mas apenas assegura a possibilidade de discutir o uso que é dado aos 
fatos pretéritos, mais especificamente o modo e a finalidade com que são lembrados. (BRASIL, 2013a).

O referido Enunciado faz referência explícita às condenações criminais. Nesse caso, além de vexatórias, as informações são passíveis de gerar preconceito, criando grandes obstáculos para a ressocialização de um ex-detento. $\mathrm{O}$ direito ao esquecimento seria, então, um mecanismo favorável à reinserção do desse sujeito na sociedade. Contudo, apesar do potencial caráter discriminatório de informações e de relativos danos ao ex-detento, o esquecimento do fato pode desfavorecer os interesses coletivos e difusos. Sendo assim, o direito ao esquecimento, para ser de fato eficaz, deve ponderar e decidir em favor do sujeito prejudicado.

Ademais, no dispositivo legal brasileiro que trata de comportamento nos ambientes digitais, Lei n ${ }^{\circ}$ 12.965, de 23 de abril de 2014, mais conhecida como Marco Civil da Internet, o legislador regulamentou, no artigo $7^{\circ}$, inciso $\mathrm{X}$, como um direito do indivíduo a solicitação de "[...] exclusão definitiva dos dados pessoais que tiver fornecido a determinada aplicação de Internet, a seu requerimento, ao término da relação entre as partes, ressalvadas as hipóteses de guarda obrigatória de registros previstas nesta Lei [...]” (BRASIL, 2014). Essa disposição legal é discutida por alguns autores como uma pequena brecha para se solicitar o direito ao esquecimento na Internet.

Como nem sempre é possível a exclusão total e definitiva de conteúdos compartilhados na Internet, tanto por questões tecnológicas como por alcance do direito, uma das estratégias utilizadas é desindexação de conteúdos com a finalidade de inibir a respectiva recuperação e mitigar o problema. Aqui, merece esclarecer que a indexação, em oposição àquela, é o processamento da informação destinado à organização para recuperação eficiente. Trata-se, nas palavras de Lancaster (2004), da representação sucinta de conteúdos de documentos, que se materializa em diferentes formatos, tais como cabeçalhos de assunto, descritores, marcadores, palavras-chave e termos indexadores, entre outros. No ambiente digital, essas representações têm o formato de ontologias, com a finalidade possibilitar a recuperação de informações.

Numa perspectiva oposta à finalidade da indexação, a desindexação trata da retirada ou exclusão de determinado conteúdo informativo de uma plataforma que contenham informações inverídicas ou violadoras do direito à privacidade e à intimidade (MORAES, 2016). Nas decisões relacionadas aos provedores de Internet e informações, criou-se o que se pode chamar de direito à desindexação. No mesmo sentido, Frajhof (2018, p. 24, grifo da autora) entende a desindexação como uma das estratégias disponíveis para a realização do direito ao esquecimento, “[...] uma vez que as mais diversas soluções dadas pelos Tribunais, e pensadas 
pela doutrina, têm se utilizado deste direito para pleitear desde a desindexação, até a retirada de conteúdo de plataformas digitais, tudo sob o mesmo rótulo do "direito ao esquecimento"”.

Entretanto, é necessário pontuar que a desindexação não é uma ramificação do direito ao esquecimento, mas uma forma de retirar informações daquele ambiente, o que também não significa que elas serão excluídas em sua totalidade, uma vez que o conteúdo informacional pode ter sido compartilhado e permanecer em outros ambientes digitais (MORAES, 2016).

Assim, as informações danosas sobre determinada pessoa veiculadas nas plataformas digitais não podem ser “eternizadas”, pois, conforme Canário (2013), quando há o confronto entre o direito à informação e o direito ao esquecimento, a doutrina entende que deve prevalecer a vontade da parte lesada, tendo em vista que o direito à dignidade humana é o princípio constitucional mais importante do ordenamento jurídico brasileiro (NUNES, 2010). As soluções, porém, não são tão pacíficas como podem parecer e não se mostram bastante favoráveis, diante dos desafios tecnológicos e jurídicos a serem enfrentados.

De fato, apagar imagens, depoimentos, dados pessoais, informação e fatos acerca de uma pessoa que estejam publicados na rede mundial de computadores se mostra uma tarefa praticamente inglória. Salvo se pensar na hipótese de uso do direito ao esquecimento que, aliado à força do Poder Judiciário, podem fazer com que haja alguma eficácia nessa empreitada. (CONSALTER, 2017, p. 25).

Um caso relevante referente à aplicação do direito ao esquecimento ocorreu no contexto da conhecida chacina da Candelária. Em 1993, na cidade do Rio de Janeiro, vários menores moradores de rua que dormiam nas escadarias da igreja de Nossa Senhora da Candelária foram surpreendidos com tiros. Na ocasião, oito pessoas foram assassinadas. O caso ganhou repercussão internacional, sendo acusados pelos crimes policiais da guarnição militar e um cidadão que exercia a profissão de serralheiro na cidade, chamado Jurandir Gomes de França. Jurandir foi preso e, três anos depois, em 2006, foi absolvido pelo crime pelo Tribunal do Júri. A rede Globo de televisão procurou-o para realizar uma matéria para o programa Linha Direta e, mesmo negando fazer parte da matéria, seu nome foi veiculado no canal. Essa atitude da emissora fez ressurgir uma série de lembranças tristes e fez com que as pessoas do seu convívio o vissem novamente como assassino. Inconformado com a situação, impetrou o pedido de direito ao esquecimento, recebido pela $4^{\mathrm{a}}$ Turma do STJ, que entendeu que o direito à dignidade humana do autor devia ser reconhecido, uma vez que foi comprovada sua inocência.

O relator do caso, Ministro Luis Felipe Salomão, assegurou em sua decisão que:

Com efeito, no conflito entre a liberdade de informação e direitos da personalidade aos quais subjaz a proteção legal e constitucional da pessoa humana -, eventual prevalência pelos segundos, após realizada a necessária ponderação para o caso concreto, encontra amparo no ordenamento jurídico, não consubstanciando, em si, a 
apontada censura vedada pela Constituição Federal de 1988. (BRASIL, 2013b, grifo do autor).

Assim, restou evidente que o Ministro teve como parâmetro, no caso, os princípios constitucionais da liberdade de informação e os direitos da personalidade, optando, então, pelo direito de personalidade do autor, que rege a vida humana. Em que pese esta decisão, ao se fazer uma pesquisa simples em um buscador como o Google, é possível encontrar o nome de Jurandir Gomes de França associado à chacina, ao programa de TV, ao pedido de esquecimento e à decisão do juiz. Mais que isso, o buscador sugere pesquisas associando o nome aos fatos. Diante disso, questiona-se a eficácia do direito ao esquecimento, perante as facilidades de busca impostas pelo avanço dos canais digitais de informação e comunicação.

É interessante questionar também os efeitos do direito ao esquecimento nos casos julgados que se tornaram precedentes. Tendo em vista que os processos são públicos e indexados em bases de dados, qualquer cidadão poderá ter acesso a eles e utilizá-los como fundamento para processos similares, bem como para artigos, comunicações, livros e monografias, entre outras publicações, que tratam da temática. Logo, mesmo não ofendendo os direitos fundamentais dos atores, os fatos narrados poderão nunca ser esquecidos em sua plenitude.

Além dos desafios tecnológicos, no Brasil, um dos impasses para se alcançar a efetividade do direito a ser esquecido tem base jurídica. Ocorre que, como bem pontuou Cavalieri Filho (2019), uma forte corrente doutrinária e jurisprudencial brasileira se opõe à exclusão de conteúdos da Internet porque esta atenta contra a liberdade de expressão e de informação. Este posicionamento se opõe ao direito ao esquecimento com base nos seguintes entendimentos:

[...] (i) o acolhimento do chamado direito ao esquecimento constitui atentado à liberdade de expressão e de imprensa; (ii) o direito de fazer desaparecer as informações que retratam uma pessoa significa perda da própria história, o que vale dizer que o direito ao esquecimento afronta o direito à memória de toda a sociedade; (iii) cogitar de um direito ao esquecimento equivale a dizer que a privacidade é a censura do nosso tempo; (iv) o direito ao esquecimento teria o condão de fazer desaparecer registros sobre crimes e criminosos perversos, que entraram para a história social, policial e judiciária, informações de inegável interesse público; (v) quando alguém se insere em um fato de interesse coletivo, mitiga-se a proteção à intimidade e privacidade em benefício do interesse público e, ademais, uma segunda publicação (a lembrança, que conflita com o esquecimento) nada mais faz do que reafirmar um fato que já é de conhecimento público. (CAVALIERI FILHO, 2019, p. 172).

A doutrina vem angariando força para a não desindexação de informações no contexto digital, utilizando-se do direito de liberdade de expressão, do direito à informação e/ou do direito à memória como defesa. Os desafios para a retirada de informações na Internet estão 
atrelados a outros direitos preservados pela lei maior brasileira, isto é, ao choque entre dois ou mais mandamentos legais. Porém, como ponderam Nunes (2010), Cavalieri Júnior (2019) e Luis Felipe Salomão (BRASIL, 2013b), há a prevalência da preservação do direito do autor da ação.

Nessa linha de discussão, outro caso emblemático de pedido de esquecimento, porém, negado pelo STJ, foi realizado pela apresentadora Maria da Graça Xuxa Meneghel. A autora solicitou que o provedor de pesquisas Google desindexasse e deixasse de sugerir, nas buscas realizadas pelos usuários, combinações entre as palavras "Xuxa" e "pedofilia". O STJ decidiu pela desobrigação do provedor, uma vez que não foi a empresa que as publicou, apenas viabilizou o acesso a elas. O Ministro Relator Celso de Mello, ao negar a pretensão de Xuxa, elucidou em sua decisão que "Não se pode, sob o pretexto de dificultar a propagação de conteúdo ilícito ou ofensivo na web, reprimir o direito da coletividade à informação." (BRASIL, 2015, p. 3). O relator embasou sua decisão em outra proferida pela Ministra Nancy Andrighi, em caso similar, a qual negou a demanda sustentando que "[...] não tem motivo para demandar contra aquele que apenas facilita o acesso a esse ato que, até então, se encontra publicamente disponível na rede para divulgação.” (BRASIL, 2012). Além disso, endossou:

Os provedores de pesquisa não podem ser obrigados a eliminar do seu sistema os resultados derivados da busca de determinado termo ou expressão, tampouco os resultados que apontem para uma foto ou texto específico, independentemente da indicação do URL [Uniform Resource Locator] da página onde este estiver inserido. (BRASIL, 2012).

Ao cidadão não cabe acionar o direito ao esquecimento contra provedores de pesquisas, tendo em vista que estes não têm como incumbência hospedar e organizar conteúdos, mas apenas indicar ao usuário links que possam conter informações de seu interesse. Nesse caso, é preciso que a pessoa lesada encontre a URL que indica a fonte de informação hospedeira, e faça a sua solicitação ao Poder Judiciário em desfavor desta, juntamente com suas alegações.

Os casos aqui discutidos demonstram que, com o advento dos novos canais de informação e comunicação, é possível evidenciar ambiguidades que rodeiam o direito ao esquecimento. Ainda não está claro em que situações deve prevalecer o interesse pessoal ou o coletivo, bem como o direito à liberdade de expressão, o direito à informação e direito à memória ou, nas palavras de Cavalieri Filho (2019), a censura de nosso tempo. Caso se decida entre um ou outro, deve-se pensar em como a Internet e os ambientes digitais diversos poderão agir em favor da decisão. Há casos em que o direito ao esquecimento deve favorecer o autor da ação como forma de preservar a sua dignidade. Em outros, porém, o interesse coletivo deve 
prevalecer, a fim de resguardar a memória da sociedade e as liberdades de informação e expressão.

\section{CONSIDERAÇÕES FINAIS}

No mundo digital, textos, imagens, áudios, vídeos e combinações com outros elementos compõem uma avalanche de conteúdos informacionais disponíveis para todos e qualquer pessoa, desde que tenham uma infraestrutura adequada de acesso. Em tese, qualquer pessoa pode fazer o download e backup de informações para si, se apropriar para diversos fins e/ou compartilhar com terceiros, posto que, muitas vezes, não há quaisquer mecanismos de controle dessas ações absolutamente eficientes. Então, quando essas informações ferem o direito de privacidade ou lesem de alguma forma outro direito do indivíduo, este pode acionar a justiça e propor a ação do direito ao esquecimento, solicitando que elas sejam desindexadas do espaço virtual.

O Poder Judiciário, como julgador de conflitos sociais e promotor da cultura da paz, diante desse problema infocomunicional, encontra-se sitiado, uma vez que, de um lado, estão o direito à liberdade de expressão e à informação resguardados, e, do outro, estão os direitos fundamentais como os de privacidade e de imagem dos indivíduos, também expressos na Constituição. O direito ao esquecimento, que consiste em um desdobramento dos princípios da inviolabilidade da vida privada e da proteção à privacidade, refere-se à benesse de o indivíduo não ser lembrado ou vinculado a situações constrangedoras ou vexatórias passadas, ainda que verdadeiras.

No Brasil, a falta de filtros ou leis específicas, porém, deixa o direito ao esquecimento à mercê de decisões jurisprudenciais que se alternam entre interesses pessoais e coletivos, dando a esse direito uma considerável carga de ambiguidade que é alimentada, também, pela natureza humana de recordação e pela capacidade de armazenamento e recuperação inerentes aos aparatos tecnológicos. É forçoso considerar que, se bem definido e caracterizado, o direito ao esquecimento atuará de forma mais incisiva e legítima no dilema entre o rememorar e o esquecer, e se tornará de fato um eficiente dispositivo a serviço da ordem social.

Agora, além das questões normativas, há outros problemas de ordens tecnológica e cultural que dificultam a efetividade desse direito e que precisam ser superados. No que se refere à primeira, considera-se a dificuldade da desindexação de informações em ambientes digitais por suas características, como, por exemplo, a rápida propagação da informação, a possibilidade de vários sites poderem hospedá-la e a inexistência, muitas vezes, de barreiras 
que dificultem o download, o backup e o compartilhamento de conteúdos, mesmo que impróprios e lesivos à ordem social. E, quanto à segunda, a capacidade humana de recordar que também se encontra ampliada pelos artefatos tecnológicos. Essa parece ser um dos principais obstáculos ao esquecimento, pois, a qualquer momento, fatos passados podem ressurgir como lembranças e, com o apoio da Internet e, notadamente, das mídias sociais, se propagar rapidamente.

Nesse sentido, a efetivação do direito ao esquecimento sempre encontrará empecilhos, pois sempre existirá a dificuldade de elencar cada site ou cada usuário que contenha informações que ferem a dignidade de outrem. Talvez as ambivalências e os desafios na efetivação do direito ao esquecimento estejam menos fundamentados na falta de legislação específica que trate dessas questões, e mais numa cultura de solidariedade e de paz, no ambiente digital. 


\section{REFERÊNCIAS}

BAUMAN, Z. Globalização: as consequências humanas. Rio de Janeiro: Jorge Zahar, 1999.

BAUMAN, Z. Modernidade líquida. Rio de Janeiro: Zahar, 2000.

BOYD, D. M; ELLISON, N. B. Social Network Sites: definition, history, and scholarship. Journal of Computer-Mediated Communication, p. 210-230, 2008.

BRASIL. [Constituição (1988)]. Constituição da República Federativa do Brasil de 1988. Brasília, DF, 2020.

BRASIL. Lei $\mathbf{n}^{\mathbf{0}}$ 12.965, de 23 de abril de 2014. Estabelece princípios, garantias, direitos e deveres para o uso da Internet no Brasil. Brasília, DF, 2014. Disponível em: http://www.plana lto.gov.br/ccivil_03/_ato2011-2014/2014/lei/112965.htm. Acesso em: 8 abr. 2020.

BRASIL. Superior Tribunal de Justiça. Enunciado no 531 da VI Jornada de Direito Civil. A tutela da dignidade da pessoa humana na sociedade da informação inclui o direito ao esquecimento. CJF - Enunciados, 2013a. Disponível em: https://www.cjf.jus.br/enunciados/ enunciado/142. Acesso em: 15 jul. 2020.

BRASIL. Superior Tribunal de Justiça (2. Turma). Agravo Regimental na Reclamação15.955/ RJ. Reclamação [...] Recurso de agravo improvido. Agravante: Maria da Graça Xuxa Meneghel. Agravado: Google Brasil Internet LTDA. Rel. Celso de Mello, 15 de setembro de 2015. Disponível em: http://redir.stf.jus.br/paginadorpub/paginador.jsp?docTP=TP\&docID=1 0241477. Acesso em: 15 jul. 2020.

BRASIL. Superior Tribunal de Justiça (3. Turma). Recurso Especial 1.316.921/ RJ. Civil e consumidor. Internet. Relação de consumo. [...] Filtragem prévia das buscas.

Desnecessidade. Restrição dos resultados. não-cabimento. Conteúdo público. Direito à informação. Recorrente: Google Brasil Internet LTDA. Recorrido: Maria da Graça Xuxa Meneghel. Relatora: Min. Nancy Andrighi, 26 de junho de 2012. JusBrasil, 29 jun. 2012. Disponível em: https://stj.jusbrasil.com.br/jurisprudencia/22026857/recurso-especial-resp1316921-rj-2011-0307909-6-stj/inteiro-teor-22026859. Acesso em: 20 jul. 2020.

BRASIL. Superior Tribunal de Justiça (4. Turma). Recurso Especial 1.335.153/RJ. Recurso Especial. Direito Civil-Constitucional. Liberdade de imprensa vs. Direitos da personalidade. [...]. Recorrente: Nelson Curi e outros. Recorrida: Globo Comunicação e Participações SA. Relator: Min. Luis Felipe Salomão, 28 de maio de 2013. JusBrasil, 10 set. 2013b. Disponível em: https://www.jusbrasil.com.br/diarios/58894349/stj-10-09-2013-pg-2577. Acesso em: 20 jul. 2020.

BUCKLAND, M. K. Information as thing. Journal of the American Society for Information Science (JASIS), v. 45, n. 5, p. 351-360, 1991.

CANÁRIO, P. Garantias da personalidade: STJ aplica "direito ao esquecimento" pela primeira vez. Revista Consultor Jurídico, jun. 2013. Disponível em: https://www.conjur.co m.br/2013-jun-05/stj-aplica-direito-esquecimento-primeira-vez-condenaimprensa?utm_source=dlvr.it\&utm_medium=facebook. Acesso em: 17 abr. 2020.

CASTELLS, M. A sociedade em rede. São Paulo: Paz e Terra, 2000. 
CAVALIERI FILHO, S. Programa de responsabilidade civil. 13. ed. São Paulo: Atlas, 2019.

CHEHAB, G. C. A privacidade ameaçada de morte. São Paulo: LTR, 2015.

CONSALTER, Z. M. Direito ao esquecimento: proteção da intimidade e ambiente virtual. Curitiba: Juruá, 2017.

DANTAS, M. A lógica do capital informação: monopólio e monopolização dos fragmentos num mundo de comunicações globais. Rio de Janeiro: Contraponto, 1996.

DEMO, P. Ambivalências da sociedade da informação. Ciência da Informação, Brasília, v. 29, n. 2, p. 37-42, maio/ago. 2000. Disponível em: http://revista.ibict.br/ciinf/article/view/8 85/920. Acesso em: 20 maio 2020.

FAORO, R. R.; ABREU, M. F.; DEMARCHI, M. Redes sociais como ferramentas de comunicação: uma síntese teórica. Ciência da Informação em Revista, Maceió, v. 4, n. 3, p. 25-39, set./dez. 2017. Disponível em: https://seer.ufal.br/index.php/cir/article/view/4097/30 33. Acesso em: 10 jul. 2020.

FERREIRA, R. B. et al. Entra em vigor o Regulamento Geral de Proteção de Dados da União Europeia. Migalhas, 2018. Disponível em: https://www.migalhas.com.br/depeso/281042/entr a-em-vigor-o-regulamento-geral-de-protecao-de-dados-da-uniao-europeia. Acesso em: 9 jul. 2020 .

FRAJHOF, I. Z. O "direito ao esquecimento" na Internet: conceito, aplicação e controvérsias. 2018. Dissertação (Mestrado em Direito) - Pontifícia Universidade Católica do Rio de Janeiro, Rio de Janeiro, 2018. Disponível em: https://www.maxwell.vrac.pucrio.br/36944/36944.PDF. Acesso em: 10 jul. 2020.

GOLDER, S.; WILKINSON, D.; HUBERMAN, B. Rhythms of social interaction: messaging within a massive online network. In: STEINIELD, C. et al. (Eds.), Proceedings of Third International Conference on Communities and Technologies. London, 2007. p. 41-66.

LAKATOS, E. M.; MARCONI, M. A. Metodologia científica. 7. ed. São Paulo: Atlas, 2017.

LANCASTER, F. W. Indexação e resumo: teoria e prática. 2. ed. Brasília: Briquet de Lemos/Livros, 2004.

LE COADIC, Y.-F. A Ciência da Informação. 2 ed. Brasília: Briquet de Lemos, 2004.

LÉVY, P. Cibercultura. Tradução; Carlos Irineu da Costa. Editora 34, São Paulo, 1999.

LOZARES, C. La teoría de redes sociales. Papers: revista de Sociologia, [S. l.], v. 48, p. 103-126, ene. 1996. Diponível em: https://papers.uab.cat/article/view/v48-lozares. Acesso em: 27 jul. 2020.

MARTELETO, R. M. Análise de redes sociais - aplicação nos estudos de transferência da informação. Ciência da Informação, Brasília, v.30, n. 1, p. 71-81, jan./abr. 2001. Disponível em: http://revista.ibict.br/ciinf/article/view/940/977. Acesso em: 14 ago. 2020. 
MARTINEZ, P. D. Direito ao esquecimento: a proteção da memória individual na sociedade da informação. Rio de Janeiro: Lumen Juris, 2014.

MARTINO, L. M. S. Teoria das mídias digitais: linguagens, ambientes, redes. 2. ed. Petrópolis, RJ: Vozes, 2015.

MAZZUOLI, V. O. Curso de direitos humanos. 6. ed. Rio de Janeiro: Forense, 2019.

MIRANDA, A. Sociedade da informação: globalização, identidade cultural e conteúdos. Ciência da Informação, Brasília, v. 29, n. 2, p. 78-88, maio/ago. 2000. Disponível em: http://revista.ibict.br/ciinf/article/view/890/925. Acesso em: 10 jul. 2020.

MORAES, M. F. D. O direito ao esquecimento na Internet no contexto das decisões judiciais no Brasil. 2016. Dissertação (Mestrado em Direito) - Universidade Presbiteriana Mackenzie, São Paulo, 2016. Disponível em: http://tede.mackenzie.br/jspui/handle/tede/2885. Acesso em: 10 jul. 2020.

NUNES, R. O princípio constitucional da dignidade da pessoa humana: doutrina e jurisprudência. 3. ed. São Paulo: Saraiva, 2010.

RICOEUR, P. A memória, a história e o esquecimento. Campinas: Unicamp, 2010.

RODRIGUES, G. M.; OLIVEIRA, E. B. Memória e esquecimento no mundo virtual: os mesmos fios tecendo uma nova trama? Liinc em revista, Rio de Janeiro, v. 11, n. 1, 2015. Disponível em: http://revista.ibict.br/liinc/article/view/3633. Acesso em: 10 jul. 2020.

SARACEVIC, T. Information Science. In: BATES, M.; MAACK, M. N. (Ed.). Encyclopedia of Library and Information Science. New York: Taylor \& Francis, 2009.

SIMÓN CATELLANO, P. El régimen constitucional del derecho al olvido digital. Valencia, Espanha: Tirante lo Blacnch. 2012.

UNITED NATIONS GENERAL ASSEMBLY (UNGA). Universal declaration of human rights. UN General Assembly. 1948. Disponível em: https://www.ohchr.org/EN/UDHR/Doc uments/UDHR_Translations/por.pdf. Acesso em: 15 jun. 2020.

WARDLE, C.; DERAKHSHAN, H. Reflexão sobre a desordem da desinformação: formatos da informação incorreta, desinformação e má informação. In: IRETON, C.; POSETTI, J.

(Orgs.). Jornalismo, fake news \& desinformação: manual para educação e treinamento em jornalismo. [S. l.]: UNESCO, 2019. p. 46-58. Disponível em: https://unesdoc.unesco.org/ark:/ 48223/pf0000368647?fbclid=IwAR14EqTCXdGhuw31WveaXmNtxK1QYRMRc_m2eouGc7 hU0RW5ieHWLRz2GNs. Acesso em: 15 ago. 2020.

WERTHEIN, J. A sociedade da informação e seus desafios. Ciência da Informação, Brasília, v. 29, n. 2, p. 71-77, maio/ago. 2000. Disponível em: http://revista.ibict.br/ciinf/articl e/view/889/924. Acesso em: 10 jul. 2020. 